\title{
Knowledge and practice on prevention of hypoglycemia among diabetic patients in South Gondar, Northwest Ethiopia: Institution based cross-sectional study
}

\author{
Girma Nega Gezie" ${ }^{*}$, Getahun Asres Alemie ${ }^{2}$ and Tadesse Awoke Ayele ${ }^{2}$ \\ ${ }^{1}$ Department of Applied Human nutrition, Faculty of chemical and Food Engineering, Bahir Dar Institute of technology, Bahir Dar University, Bahirdar, Ethiopia \\ ${ }^{2}$ Department of Epidemiology and Biostatistics, Institute of Public Health, University of Gondar, Ethiopia
}

\begin{abstract}
Hypoglycemia is an emergency life threatening condition for diabetic patients who take their medication. Proper hypoglycemia prevention relies on knowledge and self care practice. The objective of this study was to assess knowledge and practice of hypoglycemia prevention and associated factors among diabetic patients in South Gondar, Northwest Ethiopia, 2012. Institution based cross-sectional study was conducted from June-October, 2012 at governmental health institutions in South Gondar. Four hundred sixteen diabetic patients were involved in the study. A pre-tested, structured and interview administered questionnaire was used to collect data and analysis was done using SPSS version 16. Logistic regression was fitted and 95\% CI and odds ratio were presented to identify associated factors and to assess the strength of the association. For all statistical significance, the cut- off value was $\mathrm{P} \leq 0.05$. From the total study participants $105(25.5 \%)$ were found to have good knowledge about hypoglycemia prevention. Eighty nine (21.4\%) had good practice in hypoglycemia prevention. Educational status and being a member of diabetic association were found to be positively associated with knowledge and practice. Respondents who attained primary education (AOR=2.14, 95\%CI: 1.19 , 3.84), secondary education (AOR 3.02, 95\%CI: 1.53, 5.98), college and above (AOR=2.35, 95\%CI: 1.08, 5.13) were found to be more likely to have good knowledge compared with respondents who did not have formal education. Those who were members of Ethiopian diabetic association were about four times more likely to be knowledgeable (AOR=3.91, 95\%CI: 2.26, 6.77) and six times more likely to practice hypoglycemia prevention (AOR=6.08, 95\%CI: 3.34, 11.05). Knowledge and practice on hypoglycemia prevention are poor. Members of Ethiopian Diabetic Association are very low in this study. Thus the association should design and provide information tailored to patient education level.
\end{abstract}

\section{Introduction}

Hypoglycemia is an acute medical situation that occurs when blood sugar falls below the recommended level. Individuals taking diabetic medications are at increased risk of experiencing low blood sugar $[1,2]$. An estimated $2-4 \%$ of people with type 1 diabetes mellitus die from hypoglycemia each year. It might explain the "dead in bed syndrome" unexplained death of a person with type 1 diabetes occurring during night time [3]. The symptoms of low blood sugar vary from person to person, and can change over time. During the early stages a person with low blood sugar level may have sweating, trembling, feeling hungry and feeling anxious. The symptoms can become more severe, and can include difficulty of walking, weakness, visual disturbance; bizarre behavior, personality changes, confusion and unconsciousness or seizure may be observed [4] .

Knowledge about these symptoms is an important step to self care practice, because informed people are more likely to have better self care practice [5]. It is important for patients with diabetes especially, those receiving insulin to learn about hypoglycemia, and to carry some form of simple sugar with them at all times. Self care practice in diabetes management also includes dietary regulation, medication, physical activity and self monitoring of blood glucose (SMBG) [6]. Additionally, these patients should always wear an identification bracelet or tag $[7,8]$.

Several retrospective studies indicate that risk factors for hypoglycemia in 1,418 type 2 diabetes mellitus are of drug-induced and fasting as the major risk factors for sever hypoglycemia and require hospitalization [9]. Majority of hospitalized diabetic patients and their relatives had inadequate understanding of diabetes and its consequences or complications, and they had lack of confidence in own ability to manage diabetes effectively [10]. Patients knowledge about various aspect of the disease together with the understanding of the aims and objectives of various treatment outcomes have tremendous impact on patients self care practice, skills necessary to control of self blood glucose (SMBG) [11,12].

Despite the abundance of studies on self-care practice and knowledge about hypoglycemia, there are no available studies done on knowledge and practice regarding hypoglycemia prevention among diabetic patients. But this study tried to identify determinants of knowledge and practice regarding hypoglycemia among diabetic patients.

\section{Materials and methods}

Institution based cross-sectional study was conducted on public

Correspondence to: Girma Nega Gezie, Department of Applied Human nutrition, Faculty of chemical and Food Engineering, Bahir Dar Institute of technology, Bahir Dar University, Bahirdar, Ethiopia, Tel: +251-582-205925; E-mail: girma_nega@yahoo.com

Key words: hypoglycemia, Ethiopia, diabetes

Received: April 15, 2015; Accepted: May 23, 2015; Published: May 25, 2015 
Gezie GN (2015) Knowledge and practice on prevention of hypoglycemia among diabetic patients in South Gondar, Northwest Ethiopia: Institution based crosssectional study

health facilities which provide chronic illness follow-up for diabetic patients from June to October 2012 in South Gondar. There is only one zonal hospital and 90 health centers giving medical service for a total of $2,238,737$ people in the zone. Diabetes patients aged 18 years and above who were attending government health institutions in south Gondar zone were included in the study. Study subjects were recruited with proportional allocation from 1 Hospital and 9 Health centers. Then final sample was taken by simple random sampling technique from their registration book.

A structured questionnaire was developed and prepared originally in English and translated to Amharic and then translated to English to check consistency. For administering the interview, 10 diploma nurses and 4 trained BSC Nurses were recruited for data collection and supervision respectively. Training was given for data collectors and supervisors for two days about the objective, relevance, confidentiality, respondent's right, informed consent and techniques of interview for the study.

Data analysis was made by using SPSS version 16 statistical package. For all statistical significance tests, the cut- off value was $p$-value $\leq$ 0.05 . Multivariate logistic regression was used to check the effect of each explanatory variable on the dependent variable. Odds ratio and 95\% confidence interval were computed to assess the strength of the association and statistical significance.

Knowledge on hypoglycemia is defined as good glycemic control when respondents answered equal to or above the mean score of knowledge questions. Practice on hypoglycemia is defined as good self care practice when respondents answered equal to or above the mean score of practice questions.

Regular exercise means a 30 minute fast walk or riding bicycle daily. Member of Ethiopian diabetic association is diabetic patient who are voluntary to be member of the association and governed on the rule and the regulation of the association.

Ethical clearance was obtained from University of Gondar and permission letter was taken from Amhara Regional Health Bureau and South Gondar zone health department.

\section{Results}

\section{Socio demographic characteristics of participants}

A total of 416 diabetes mellitus patients were included in the study with response rate of $98.6 \%$. The mean age of the respondents was 39.1 with S.D of \pm 1.4 years. One hundred ninety six (47.1\%) of them were urban residents. One hundred fifty four (37\%) participants did not have formal education; 307 (88.2\%) respondents were Orthodox Christian in religion. One hundred forty four (34.6\%) of the respondents were unemployed, $201(53.1 \%)$ of respondents were married. From the total participants only $70(16.8 \%)$ were found to be members of the Ethiopian diabetic association (Table1).

\section{Knowledge regarding hypoglycemia}

From all knowledge questions, 105 (25.5\%) respondents had good knowledge in hypoglycemia prevention; however in specific question $213(51.2 \%)$ participants had poor knowledge in identifying symptoms of hypoglycemia. With regard to the effect of exercise, majority 365 (87.7\%) didn't know that exercise aggravated hypoglycemia, 348 (83\%) respondents knew that alcohol intake leads to hypoglycemia (Table 2).
Table 1. Socio demographic Characteristic of participants, South Gondar, NorthwestEthiopia, October, 2012

\begin{tabular}{|c|c|c|}
\hline Variable & Frequency $(n=416)$ & Percent (\%) \\
\hline \multicolumn{3}{|l|}{ Age } \\
\hline $18-34$ & 208 & 50 \\
\hline $35-64$ & 196 & 47.1 \\
\hline$\geq 65$ & 12 & 2.9 \\
\hline Total & 416 & 100 \\
\hline \multicolumn{3}{|l|}{ Sex } \\
\hline Male & 259 & 62.3 \\
\hline Female & 157 & 37.7 \\
\hline Total & 416 & 100 \\
\hline \multicolumn{3}{|l|}{ Residence } \\
\hline Rural & 220 & 52.9 \\
\hline Urban & 196 & 47.1 \\
\hline Total & 416 & 100 \\
\hline \multicolumn{3}{|l|}{ Religion } \\
\hline Orthodox & 367 & 88.2 \\
\hline Muslim & 49 & 11.8 \\
\hline Total & 416 & 100 \\
\hline \multicolumn{3}{|l|}{ Ethnicity } \\
\hline Amhara & 412 & 99.0 \\
\hline Tigrie & 4 & 1.0 \\
\hline Total & 416 & 100 \\
\hline \multicolumn{3}{|l|}{ Marital status } \\
\hline Single & 114 & 27.4 \\
\hline Married & 221 & 53.1 \\
\hline Divorced & 81 & 19.5 \\
\hline Total & 416 & 100 \\
\hline \multicolumn{3}{|l|}{ Educational status } \\
\hline No formal education & 154 & 37.0 \\
\hline Primary & 145 & 34.9 \\
\hline Secondary & 69 & 16.6 \\
\hline College and above & 48 & 11.5 \\
\hline Total & 416 & 100 \\
\hline \multicolumn{3}{|l|}{ Occupation } \\
\hline Unemployed & 144 & 34.6 \\
\hline Government & 99 & 23.8 \\
\hline Private & 173 & 41.6 \\
\hline Total & 416 & 100 \\
\hline \multicolumn{3}{|l|}{ Economical status } \\
\hline$\leq 400$ Eth birr & 117 & 28.1 \\
\hline $401-700$ & 106 & 25.5 \\
\hline $701-999$ & 42 & 10.1 \\
\hline$\geq 1000$ & 151 & 36.3 \\
\hline Total & 416 & 100 \\
\hline \multicolumn{3}{|c|}{$\begin{array}{l}\text { Membership of diabetic } \\
\text { association }\end{array}$} \\
\hline No & 346 & 83.2 \\
\hline Yes & 70 & 16.8 \\
\hline Total & 416 & 100 \\
\hline
\end{tabular}

\section{Practice regarding hypoglycemia}

From the total respondents eighty nine (21.4\%) study subjects had good practice in hypoglycemia prevention. Three hundred ninety three (94\%) of participants take their medication at the right time; 244 (58\%) had good practice by taking snack and 151 (36\%) carrying table sugar to treat hypoglycemia (Table 3 ). 
Gezie GN (2015) Knowledge and practice on prevention of hypoglycemia among diabetic patients in South Gondar, Northwest Ethiopia: Institution based crosssectional study

Table 2. Knowledge regarding hypoglycemia prevention, South Gondar, NorthwestEthiopia, October, $2012(\mathrm{n}=416)$.

\begin{tabular}{|l|c|c|}
\hline \multicolumn{1}{|c|}{ Variable } & Good knowledge n (\%) & Poor knowledge n (\%) \\
\hline Symptom of hypoglycemia & $203(48.8)$ & $213(51.2)$ \\
\hline DM diet & $373(89.7)$ & $43(10.3)$ \\
\hline Effect of exercise & $51(12.3)$ & $365(87.7)$ \\
\hline Effect of break fast & $231(55.5)$ & $185(44.5)$ \\
\hline Effect of alcohol on hypoglycemia & $348(83.6)$ & $68(16.4)$ \\
\hline Effect of bean on hypoglycemia & $287(69.0)$ & $129(31.0)$ \\
\hline Effect of wheat on blood sugar & $377(90.6)$ & $39(9.4)$ \\
\hline
\end{tabular}

Table 3. Practice regarding hypoglycemia prevention, South Gondar, Northwest- Ethiopia, October $2012(\mathrm{n}=416)$

\begin{tabular}{|l|c|c|}
\hline Variables & Good practice n (\%) & Poor practice n (\%) \\
\hline Self blood glucose monitoring at home & $32(7.7)$ & $384(92.3)$ \\
\hline Taking medication at the right time & $393(94.5)$ & $23(5.5)$ \\
\hline Taking snack & $244(58.7)$ & $172(41.3)$ \\
\hline Taking carbohydrate diets irregularly & $153(36.8)$ & $263(63.2)$ \\
\hline Carry table sugar to treat hypoglycemia & $151(36.3)$ & $265(63.7)$ \\
\hline Coming in regular appointments & $388(93.3)$ & $28(6.7)$ \\
\hline Carrying diabetic identification card & $56(13.5)$ & $360(86.5)$ \\
\hline Regular exercise & $123(29.6)$ & $293(70.4)$ \\
\hline Duration of exercise & $74(17.8)$ & $342(82.2)$ \\
\hline Adjustment of medication & $193(46.4)$ & $223(53.6)$ \\
\hline Hypoglycemia treatment & $245(58.9)$ & $171(41.1)$ \\
\hline
\end{tabular}

Table 4. Association of Selected demographic variables with Hypoglycemia Knowledge in South Gondar, Ethiopia, October $2012(\mathrm{n}=416)$.

\begin{tabular}{|l|c|c|c|c|}
\hline Variable & Good & \multicolumn{1}{|c|}{ Poor } & COR (95\%CI) & AOR (95\%CI) \\
\hline Residence & $47(21.4)$ & $173(78.6)$ & 1.00 & \\
\hline Rural & $58(29.6)$ & $138(70.4)$ & $1.55(0.99,2.41)$ & \\
\hline Urban & & & & \\
\hline $18-34$ & $57(27.4)$ & $151(72.6)$ & 1.00 & \\
\hline $35-64$ & $47(24)$ & $149(76)$ & $0.84(0.53,1.31)$ & \\
\hline$\geq 65$ & $1(8.3)$ & $11(91.7)$ & $0.24(0.03,1.91)$ & \\
\hline Marital status & & & & \\
\hline Single & $29(25.4)$ & $85(74.6)$ & 1.00 & \\
\hline Married & $55(24.9)$ & $166(75.1)$ & $0.97(0.58,1.63)$ & \\
\hline Divorced & $21(25.9)$ & $60(74.1)$ & $1.03(0.54,1.97)$ & \\
\hline Education & & & & \\
\hline No formal education & $23(14.9)$ & $131(85.1)$ & 1.00 & 1.00 \\
\hline Primary & $41(28.3)$ & $104(71.7)$ & $2.25(1.27,3.98)$ & $\mathbf{2 . 1 4}(\mathbf{1 . 1 9 , 3 . 8 4})$ \\
\hline Secondary & $26(37.7)$ & $43(62.3)$ & $3.44(1.78,6.65)$ & $\mathbf{3 . 0 2}(\mathbf{1 . 5 3 , 5 . 9 8 )}$ \\
\hline College and above & $15(31.3)$ & $33(68.7)$ & $2.59(1.22,5.50)$ & $\mathbf{2 . 3 5 ( 1 . 0 8 , 5 . 1 3 )}$ \\
\hline Occupation & & & & \\
\hline Unemployed & $37(25.7)$ & $107(74.3)$ & 1.00 & \\
\hline Government & $33(33.3)$ & $66(66.7)$ & $1.45(0.83,2.53)$ & \\
\hline Private & $35(20.2)$ & $138(79.8)$ & $0.73(0.43,1.24)$ & \\
\hline Member of DM association & & & & \\
\hline No & $69(11.3)$ & $277(88.7)$ & 1.00 & \\
\hline Yes & & & & \\
\hline & & & \\
\hline
\end{tabular}

\section{Determinants of knowledge and practice on hypoglycemia prevention}

Multivariate logistic regression showed that, being a member of the Ethiopian Diabetic association, completed their primary school, secondary school, college and above were significantly and independently associated with knowledge and practice of hypoglycemia prevention.

Diabetic patients who attained primary education were $(\mathrm{AOR}=2.14$, 95\%CI: 1.19, 3.84), secondary education (AOR 3.02, 95\%CI: 1.53, 5.98) and completed college and above $(\mathrm{AOR}=2.35,95 \% \mathrm{CI}$ : $1.08,5.13)$ were more likely to have good knowledge than respondents who had not formal education. Being the member of diabetic association has positively associated with knowledge $(\mathrm{AOR}=3.91,95 \% \mathrm{CI}: 2.26,6.77)$ (Table 4).

With regard to practice, those who have primary, secondary and college and above education were $(\mathrm{AOR}=2.20,95 \% \mathrm{CI}: 1.07,4.52)$, $(\mathrm{AOR}=5.29,95 \% \mathrm{CI}: 2.43,11.52),(\mathrm{AOR}=8,95 \% \mathrm{CI}: 3.17,17.51)$ more likely to have good practice than those were not formal education respectively. Being the members of diabetic association were 6 times (95\%CI: $3.34,11.05)$ more likely to have good practice than who were not member of diabetic association. However residence, occupation, income and sex of respondents were not significantly associated with hypoglycemia prevention knowledge and practice (Table 5).

\section{Discussion}

Knowledge about symptom of hypoglycemia is an important step to self care practice for diabetic patients, because informed people are more likely to have better self care practice [5].The goals in diabetes education consists in improving metabolic control, preventing acute and chronic complications and improving one's quality of life at reasonable cost [13]. Self care practice in diabetic management includes dietary regulation, medication, physical activity self blood monitoring at home (SMBG) and always wearing an identification bracelet or tag $(7,8)$.

From all study subjects 105(25.5) participants had good knowledge in hypoglycemia prevention. Forty three (41\%) female participants

Table 5. Association of Selected demographic variables with Hypoglycemia Practice in South Gondar, Ethiopia, October 2012.

\begin{tabular}{|l|c|c|c|c|}
\hline Variable & Good & \multicolumn{1}{|c|}{ poor } & COR (95\%CI) & COR (95\%CI) \\
\hline Address of respondent & & & & \\
\hline Rural & $28(12.7)$ & $192(87.3)$ & 1.00 & \\
\hline Urban & $61(31.1)$ & $135(68.9)$ & $3.10(1.88,5.10)$ & \\
\hline Religion & & & & \\
\hline Orthodox & $73(19.9)$ & $294(80.1)$ & 1.00 & \\
\hline Muslim & $16(32.7)$ & $33(67.30$ & $1.95(1.02,3.74)$ & \\
\hline Education & & & & \\
\hline Illiterate & $14(9.1)$ & $140(90.9)$ & 1.00 & 1.00 \\
\hline Primary & $28(19.3)$ & $117(80.7)$ & $2.39(1.20,4.76)$ & $\mathbf{2 . 2 0}(\mathbf{1 . 0 7 , 4 . 5 2})$ \\
\hline Secondary & $26(37.7)$ & $43(62.3)$ & $6.05(2.90,12.60)$ & $\mathbf{5 . 2 9}(\mathbf{2 . 4 3 , 1 1 . 5 2})$ \\
\hline College and above & $21(43.8)$ & $27(56.2)$ & $7.78(3.52,17.17)$ & $\mathbf{8 . 1} \mathbf{( 3 . 5 3 , 1 8 . 9 5 )}$ \\
\hline Occupation & & & & \\
\hline Unemployed & $30(20.8)$ & $114(79.2)$ & 1.00 & \\
\hline Government & $39(39.4)$ & $60(60.6)$ & $2.47(1.40,4.37)$ & \\
\hline Private & $20(11.6)$ & $153(88.4)$ & $0.50(0.27,0.92)$ & \\
\hline Income & & & & \\
\hline$\leq 400$ birr & $21(17.9)$ & $96(82.1)$ & 1.00 & \\
\hline $401-700$ & $15(14.2)$ & $91(85.8)$ & $0.75(0.36,1.55)$ & \\
\hline $701-999$ & $9(21.4)$ & $33(78.6)$ & $1.25(0.52,2.99)$ & \\
\hline$\geq 1000$ birr & $44(29.1)$ & $107(70.9)$ & $1.88(1.04,3.38)$ & \\
\hline Member of Dm association & & & & \\
\hline No & $53(15.3)$ & $293(84.7)$ & 1.00 & \\
\hline Yes & $36(51.4)$ & $34(48.6)$ & $5.85(3.37,10.17)$ & $\mathbf{6 . 0 8}(\mathbf{3 . 3 4 , 1 1 . 0 5 )}$ \\
\hline & & & & \\
\hline
\end{tabular}


were knowledgeable in hypoglycemia prevention. This is relatively low when compared to study conducted in Kuwazulu Natal, South Africa were $66.9 \%$ had good knowledge [14]. This might be due to time variation and Sociodemographic differences.

Two hundred three $(49.8 \%)$ of participants could identify symptom of hypoglycemia, but study conducted on type 2 diabetics in Kampala, Uganda showed that only $36 \%$ of study subjects could identify symptoms of hypoglycemia [15].

The higher knowledge in this study might be due to accessibility of health services recently giving chronic follow up for diabetic patients, so participants might get more information to hypoglycemia and diabetic complication.

Being a member of diabetic association create chance to get information about diabetic complication, and acquiring knowledge and practice on hypoglycemia prevention. Only $70(16.8 \%)$ patients were member of Ethiopian Diabetic Association. This is low compared to study conducted in Bangladesh $87.50 \%$ diabetes patients were member of diabetes association [16,17]. The reason of this higher difference might be Ethiopian diabetic association not still decentralized to far urban areas.

Self care practice was early warning method for diabetes emergency conditions. In this study only $7.7 \%$ practiced self blood glucose test at home which is lower than study conducted in Qatar, where $60.5 \%$ of respondents reported that they were monitoring their blood glucose at home. This might be due to financial barrier to self monitoring of blood glucose test (SBGT) apparatus, fear of pain related to finger prick and health professionals focus only dietary advice than self blood monitoring [18].

Even though wearing an identification band is need for diabetic patient, only $13.5 \%$ had practice of carrying identification card in this study. It is lower with the study conducted in Pakistan (18\%) [19]. The difference might be healthcare providers and patients were not giving attention for the benefit of carrying ID cards to prevent hypoglycemia and hyperglycemia related complication.

In conclusion, knowledge and practice of hypoglycemia prevention among diabetic patients were low as revealed by this study. At least primary education and being the member of diabetic association were associated significantly with both knowledge and practice of hypoglycemia prevention. Lack of knowledge in identification of symptoms of hypoglycemia and in carrying of identification band and self blood glucose monitoring at home, to treat and to prevent hypoglycemia was poor.

\section{Acknowledgments}

We would like to acknowledge the University of Gondar Institution of Public Health, World Bank nutrition project and Department of Human Nutrition for their unlimited supports. We gave our great thanks for data collection facilitators for their genuine dedication and effort shown during the data collection. We also express our heartfelt gratitude for respondents giving their precious time during interview.

\section{References}

1. U.S. Hypoglycemia (2008) National Institute of Health Puplication. (09- 3926): 1-10.

2. Philip E, Irene E, Michael M, et al. (2010) Hypoglycemia in type 1 Diabetes mellitus, Pathophysiology, Prevalence and Prevention. Endocrinol Metabol clin North Am 39: 2-3. [Crossref]

3. Cryer PE, Axelrod L, Grossman AB, Heller SR, Montori VM, et al. (2009) Evaluation and management of adult hypoglycemic disorders: an Endocrine Society Clinical Practice Guideline. J Clin Endocrinol Metab 94: 709-728. [Crossref]

4. David M (2012) Diabetic hypoglycemia. Meds cape's 1: 10-11

5. Peyrot M, Rubin RR (1994) Modeling the effect of diabetes education on glycemic control. Diabetes Educ 20: 143-148. [Crossref]

6. Suzanne C, Brenda G (1995) Medical surgical nursing. Philadelphia: Lippincott, (10th Edn.), pp: 1178-1180.

7. Siguroardottir A (2004) Model of factors affecting self care in diabetes. Journal of Clinical Nursing 1: 3011-3014.

8. Anne S, Rémi R, Irene S, et al. (2008) Barriers to Physical Activity among Patients with Type 1 Diabetes, knowledge and practice of nutrition related hypoglycemia and related factors in diabetic patient. Diabetic care 31: 2108-2109. [Crossref]

9. Seltzer HS (1989) Drug-induced hypoglycemia. A review of 1418 cases. Endocrinol Metab Clin North Am 18: 163-183. [Crossref]

10. Zeinab H (2011) Health and Knowledge Progress among Diabetic Patients after Implementation of a Nursing Care Program. Diabetic metabolism, Nursing College, Hellwan University, 2-10.

11. Shaheen C, Zia U, Tofail A, Sharifa N (2005) Knowledge assessment of diabetes patients. Bangladesh Journal of Medical Science 5: 8-16.

12. Rafique G, Azam S, White F (2006) Diabetes knowledge, beliefs and Practices among people with diabetes attending a university hospital in Karachi, Pakistan. Eastern Mediterranean health journal 12: 591-593. [Crossref]

13. Liudmila M, Maria L, Zanetti M, et al. (2008) Knowledge of diabetic patients about their disease before and after implementing a diabetes education program. WHO Collaborating Centre for Nursing Research Development, Brazil 16: 231-237. [Crossref]

14. Moodley L, Bphar M (2007) An assessment of level of knowledge about diabetes mellitus among diabetic patients in primary care settings. Family practice 49: 16.

15. Baumann LC, Opio CK, Otim M, Olson L, Ellison S (2010) Self-care beliefs and behaviors in Ugandan adults with type 2 diabetes. Diabetes Educ 36: 293-300. [Crossref]

16. Zia U, Sharifa N (2005) Knowledge assessment of diabetes patients. Bangladesh Journal of medical science 5: 12-16.

17. Ethiopian diabetic association (2012) Activities of Ethiopian diabetic association

18. Mohsen M, Aizeldin E, Mohamed G (2011) Knowledge and Practice of Type 2 Diabetic Patients Attending Primary Health Care in Qatar. The Journal of the south Asia primary care research network 2: 1-9.

19. Gul N (2010) Knowledge, attitudes and practices of type 2 diabetic patients. J Ayub Med Coll Abbottabad 22: 128-131. [Crossref]

20. Yngve V (2011) Sweat meter could alert diabetes patients about low blood sugar Research magazine Apollon University of Oslo, Norway: 1-11.

21. Workgroup on Hypoglycemia, American Diabetes Association (2005) Defining and reporting hypoglycemia in diabetes: a report from the American Diabetes Association Workgroup on Hypoglycemia. Diabetes Care 28: 1245-1249. [Crossref]

22. Nitiyanant W, Chetthakul T, Sang-A-kad P, Therakiatkumjorn C, Kunsuikmengrai K, et al. (2007) A survey study on diabetes management and complication status in primary care setting in Thailand. J Med Assoc Thai 90: 65-71. [Crossref]

23. Fertig B, Simmons D, Martin D (1995) Therapy for diabetes In America. Bethesda: National Institutes of Health, (2nd Edn).

24. Catherine A, Tamara L, Mari P (2001) Risk Factors for Frequent and Severe Hypoglycemia in Type 1 Diabetes, Preventive Medicine. Diabetic Care 24: 1878-1880.

25. Jennings A, Wilson R, Ward J (1989) Symptomatic hypoglycemia in Non insulin dependant diabets mellitus patients treated with oral hypoglycemic agents. Diabetes Care 3: 163-183.

26. Gerich J (1989) Oral hypoglycemic agents. North England Journal of Medicine 3 : 1231-1241.

27. Elzubier A (2001) Knowledge of hypoglycemia by primary health care centers registered diabetic patients, Department of Family \& Community Medicine. Saudi Medical Journal 22: 219-222. 
Gezie GN (2015) Knowledge and practice on prevention of hypoglycemia among diabetic patients in South Gondar, Northwest Ethiopia: Institution based crosssectional study

28. Brazeau AS, Rabasa-Lhoret R, Strychar I, Mircescu H (2008) Barriers to physical activity among patients with type 1 diabetes. Diabetes Care 31: 2108-2109. [Crossref]

29. Zaheera S, Salah R, Munira A (2010) A study of knowledge attitude and practices of Saudi women towards Diabetes Mellitus in Al-Qassim Region. The International Journal of Health 11: 3-11.

30. Central statistics agency (2007) Census of Ethiopian Central Statistics.

Copyright: $@ 2015$ Gezie GN. This is an open-access article distributed under the terms of the Creative Commons Attribution License, which permits unrestricted use, distribution, and reproduction in any medium, provided the original author and source are credited. 